\section{Kidney \\ Blood Pressure Research}

\title{
Hemodialysis Experience of a Large Group of Syrian Refugees in Turkey: All Patients Deserve Effective Treatment
}

\author{
Meltem Gursu ${ }^{a} \quad$ Mustafa Arici $^{b} \quad$ Kenan Ates $^{c} \quad$ Rumeyza Kazancioglu ${ }^{a}$ \\ Pinar Guneser Yavas ${ }^{d} \quad$ Murat Ozturk $^{\mathrm{e}}$ Bulent Altun ${ }^{\mathrm{b}}$ Turgay Arinsoy ${ }^{f}$
}

aBezmialem Vakif University Faculty of Medicine, Division of Nephrology, Istanbul, 'bacettepe University Faculty of Medicine, Department of Nephrology, Ankara, 'Ankara University Faculty of Medicine, Department of Nephrology, Ankara, dMinistry of Health, General Directorate of Health

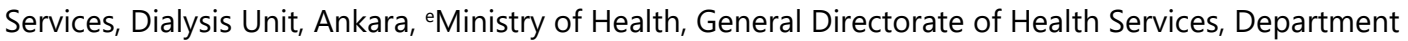
of Organ, Tissue Transplantation and Dialysis, Ankara, ${ }^{\mathrm{f}} \mathrm{Gazi}$ University Faculty of Medicine, Department of Nephrology, Ankara, Turkey

\section{Key Words}

Hemodialysis $\bullet$ Refugee $・$ Dialysis adequacy $\bullet$ Vascular access

\begin{abstract}
Background/Aims: Refugee dialysis is a worldwide growing dilemma with limited experience. This report presents the largest hemodialysis (HD) patient registry data of Syrian refugees in Turkey. Methods: Demographic, clinical, laboratory, and dialysis practice data of 345 Syrian HD patients during one year were collected and analyzed. Results: There were 345 prevalent Syrian HD patients at the end of 2016. Majority of the patients were placed in the Southeast Anatolian Region. The majority of the patients (74.8\%) are in the age range of 20-64 years. Dialysis vintage in Turkey is less than 12 months in $20.8 \%$ and less than one month in $29.3 \%$ of patients. The vascular access was arteriovenous fistula in the majority of patients $(72.5 \%)$. $\mathrm{Kt} / \mathrm{V}$ is over 1.7 in $57 \%$, serum albumin is above $35 \mathrm{~g} / \mathrm{L}$ in $65.8 \%$ and hemoglobin level is more than $100 \mathrm{~g} / \mathrm{L}$ in $\% 65.2$ of the patients. The ratio of patients with serum phosphorus level of $1.13-1.77 \mathrm{mmol} / \mathrm{L}$ was $56.2 \%$. Twenty Syrian HD patients (14 male, 6 female) died within the year 2016 and annual mortality rate was $5.7 \%$. Conclusion: This study with the largest number of Syrian refugees undergoing maintenance hemodialysis showed good dialysis practices, acceptable values for dialysis adequacy and biochemical parameters along with lower mortality compared to native HD population of Turkey. Longer follow up will enrich the knowledge related to care of refugee population in all over the world.
\end{abstract}




\section{Kidney Blood Pressure Research}

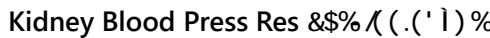

\begin{tabular}{l|l}
\hline DOI: $10.1159 / 000498832$ & (c) 2019 The Author(s). Published by S. Karger AG, Basel
\end{tabular}

Published online: 22 February 2019

www.karger.com/kbr

Gursu et al.: Syrian Refugee Hemodialysis Experience in Turkey

\section{Introduction}

A refugee is someone who has been forced to flee his or her country because of persecution, war or violence [1]. Syrian conflict has started in 2011 and displaced millions (approximately 4.8 millions) to seek asylum in several countries, mostly the neighboring ones. Turkey has hosted the largest number of refugees where the population of Syrian refugees outnumbered almost three millions [2]. This has definitely placed a great burden on the Turkish government, economy and health care. Turkey tried to cover almost all acute (traumas, injuries, infections) and chronic health problems (diabetes mellitus, cancer, end stage renal disease) of the refugees from the first days of the crisis.

Healthcare reimbursement for refugee patients differs from country to country with no standard. Undocumented immigrants in USA were ineligible for federally funded government programs like Medicare and non-emergency Medicaid [3]. A recent study has shown that undocumented immigrants who were excluded from regular scheduled dialysis experience debilitating, potentially life-threatening physical symptoms and psychosocial distress [4]. Mean 5-year relative hazard of mortality for undocumented immigrants who received emergency-only hemodialysis was found to be more than 14-fold higher than for those who received standard hemodialysis [5]. In Turkey; Syrian people are under the Temporary Protection (SRTP) status. Turkish Disaster and Emergency Management Authority (AFAD) was caring for Syrian refugees in temporary sheltering centers and then also in the cities where they moved independently since April 2011 [6]. Turkish Government covered all health expenditures for acute and chronic diseases of registered Syrian people in primary, secondary and tertiary health centers, and even in private clinics or hospitals [7].

The crisis and the ensuing population movement in Syria have seriously affected the end stage kidney disease (ESKD) patients who are undergoing hemodialysis (HD) treatment. The exact data about the number of HD patients in Syria during this crisis was unknown. The annual report of renal replacement therapy (RRT) issued by the Syrian Ministry of Health in 2005 showed that there were 2750 new HD patients [8]. Moukeh et al. [9] reported that a total of 550 dialysis patients lived in the city of Aleppo in 2009.

Data about the outcome of Syrian refugee HD patients are very limited in the literature. Isreb et al. [10] compared two charity-run HD facilities in Syria; one in a besieged area in Damascus and one near the Turkish border. After 12 months of follow-up of 60 patients, $48 \%$ of patients died in the besieged area while the mortality rate was $21 \%$ in the facility near Turkish border. Another study from southeast region of Turkey was conducted with refugee children [11]. Among 130 children seeking renal care, 30 had chronic kidney disease. Eighteen had ESKD at the time of admission when dialysis was started $7 \mathrm{HD}$ and 11 PD). Only eight of these patients had regular follow-up visits [11]. A recent survey among 57 Syrian patients receiving dialysis in Jordan showed inadequate care with poor anaemia control, limited availability of medications and many missed dialysis sessions [12]. Isreb et al. reviewed 12 reports about the care of ESKD patients at times of armed conflict which leads to staff and resource deficiencies. They found that adequate dialysis was difficult to provide and mortality increased at these time periods [13].

In this report, we present the largest HD patient registry data of Syrian refugees $(n=345)$ who have regular, maintenance HD treatment in Turkey.

\section{Materials and Methods}

Demographic, clinical and laboratory data of all HD patients are collected via a web-based program called 'Transplantation Dialysis Follow-up System' (TDIS-Transplantasyon Diyaliz Izlem Sistemi) by the Ministry of Health of Turkish Republic. In this system, dialysis orders, medical treatments and dialysis adequacy parameters are reported on a monthly basis. Patients with acute kidney injury requiring HD are 


\section{Kidney Blood Pressure Research}

not recorded in this system. The system is also operative for all dialysis schedules carried on Syrian refugees for which all dialytic and medical expenditures are fully covered by the Turkish social security system.

Data for prevalent Syrian HD patients were received from TDIS by the end of 2016. Peritoneal dialysis patients and transplanted patients were not included.

The data included age and gender, region and city, and the type of dialysis facility (public or private), the modality of HD treatment (in-center HD, hemodiafiltration, hemofiltration and home HD), total vintage of dialysis and the duration of dialysis in Turkey in years and months, respectively.

Basic dialysis practice data was also recorded including vascular access, frequency of dialysis sessions, type of dialyzers (low-flux or high-flux) and blood flow rate, single pool Kt/V value determined monthly as a measure of dialysis adequacy. Serum blood urea nitrogen (BUN), creatinine, sodium, potassium, albumin, hemoglobin, calcium, phosphorus and parathyroid hormone (PTH) levels were recorded for each patient.

Data about the use of antihypertensive medications, erythropoiesis stimulating agents (ESAs), iron, phosphorus binders (calcium acetate, calcium carbonate, sevelamer, and aluminum), parenteral or oral vitamin $\mathrm{D}$, vitamin $\mathrm{D}$ analogues and calcimimetics were also retrieved from the database.

Serological tests for hepatitis B, C and human immunodeficiency virus (HIV) were documented.

Annual death rate and the causes of mortality were also obtained from the database.

Statistical analysis was conducted by SPSS (Statistical Package for Social Sciences) program. Numerical variables (age, total duration of dialysis, duration of dialysis in Turkey, blood flow rate, Kt/V, laboratory measures) were presented as the number and percentage of patients within predefined limits. Nonnumeric variables (gender, region and the city in which dialysis treatment was applied, the modality of HD, vascular access, type of the dialyzer, use of medications defined in the methods section, serology for hepatitis B, C and HIV, and cause of death) were expressed as the number of patients and the percentage within the study population. $P$ values less than 0.05 were considered statistically significant.

\section{Results}

\section{Demographic and clinical parameters}

There were 345 prevalent Syrian HD patients at the end of 2016 according to TDIS data. Majority of the patients were placed in the Southeast Anatolian $(n=129 ; 37.4 \%)$ and Mediterranean Regions $(n=84 ; 24.4 \%)$ of Turkey, as they were the closest regions to the Syrian border. The rest of the refugees $(n=117,38.2 \%)$ were distributed to the other regions of Turkey. Almost one third of the patients $(n=109,31.6 \%)$ were living in two cities, namely Sanliurfa and Gaziantep, which are the biggest neighboring cities to the Syrian border. Majority of the refugees were treated in public government hospitals $(n=232 ; 67.3 \%)$, one third $(n=105 ; 30.4 \%)$ in private centers and only eight patients $(2.3 \%)$ in University Hospitals.

334 patients $(96.8 \%)$ had standard in-center HD treatment; one (0.3\%) had hemodiafiltration while data was missing for 10 patients $(2.9 \%)$.

The age distribution of the Syrian HD patients is shown in Fig. 1. 48.4\% of patients were female and $51.6 \%$ were male.

Durations of dialysis from the start and within Turkey are presented in Table 1. $20.8 \%$ of the patients had dialysis duration within Turkey more than 12 months, while $29.3 \%$ had dialysis for less than three months in Turkey (Table $1)$.

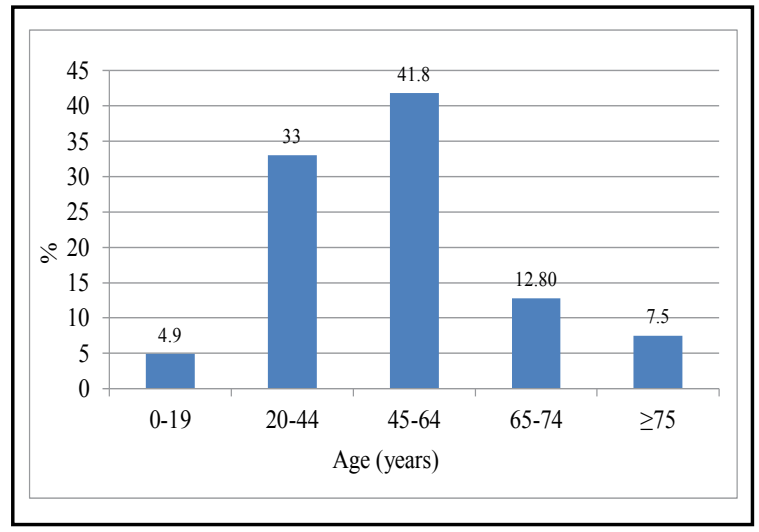

Fig. 1. The age distribution of the Syrian hemodialysis patients. 


\section{Kidney \\ Blood Pressure Research}

The prevalence of positive serology for hepatitis B and hepatitis $\mathrm{C}$ were $2.0 \%$ and $6.7 \%$, respectively. None of the Syrian patients had positive serology for HIV.

\section{Dialysis practice parameters}

The vascular access was arteriovenous fistula in $72.5 \%$ $(\mathrm{n}=250)$, tunneled catheter in $18.2 \% \quad(\mathrm{n}=63)$, untunnelled catheter in $9.0 \% \quad(n=31)$ and arteriovenous graft in $0.3 \%$ $(n=1)$ of the patients.

The majority of patients (91.9\%) were scheduled to have thrice weekly HD treatment. Dialysis session duration was four hours for all patients.

The data about the type of the dialyzer, and blood flow rate is presented in Table 2 .

Dialysis adequacy, biochemicalparameters and medical treatment

The distribution of patients according to $\mathrm{Kt} / \mathrm{V}$ value, serum albumin and hemoglobin levels are presented in Fig. 2. The ratio of patients with Kt/V value of 1.2 or lower was $22.3 \%$. 34.2\% of the Syrian HD patients had serum albumin level below $35 \mathrm{~g} / \mathrm{L}$. Hemoglobin level below $100 \mathrm{~g} / \mathrm{L}$ was recorded in $34.8 \%$ of patients.

Serum phosphorus, calcium and PTH levels are presented in Fig. 3. The ratio of patients with serum phosphorus level of 1.13-1.77 mmol/L was 56.2\%. PTH level in the range of $15.9-31.8 \mathrm{pmol} / \mathrm{L}$ was seen in $22.5 \%$ of the patients. The ratio was $55 \%$ including patients with PTH level between $15.9 \mathrm{pmol} / \mathrm{L}$ and $63.6 \mathrm{pmol} / \mathrm{L}$.

Almost two thirds of Syrian patients were not using any antihypertensive medication (62.3\%). 199 patients (57.7\%) were currently using an ESA. $70(20.3 \%)$ patients have used ESA previously, while $76(22.0 \%)$ patients never required ESA treatment. Iron treatment was used in $62.3 \%$ of the patients.

Phosphorus binders were prescribed to 273 Syrian patients $(79.1 \%)$. The drugs used with decreasing order of frequency were calcium acetate $(n=217)$, sevelamer $(n=36)$, calcium carbonate $(n=11)$ and other phosphorus binders $(n=25)$. Other medications used for regulation of mineral bone disorders were intravenous vitamin $D(n=130)$, oral vitamin $\mathrm{D}(\mathrm{n}=46)$ and vitamin $\mathrm{D}$ analogs $(\mathrm{n}=12)$.

The data of Syrian patients were compared by the Turkish patients' data of whom were retrieved from Registry of Turkish Society of Nephrology [14] (Table 3). The type of the dialyzers used was similar in both populations, mostly being high flux dialyzers. The blood flow rates between $300-400 \mathrm{ml} / \mathrm{min}$ were similar in Syrian and Turkish patients $(77.0 \% \mathrm{vs}$. $69.5 \%$ ). The ratio of patients with $\mathrm{Kt} / \mathrm{V}$ value over 1.2 was $77.7 \%$ among Syrian patients while this ratio was $90.2 \%$ in Turkish patients $(p<0.001)$. Serum albumin level was above 35 $\mathrm{g} / \mathrm{L}$ in $65.8 \%$ of Syrian patients and $86.6 \%$ of Turkish patients. Hemoglobin level was in the range of $100-120 \mathrm{~g} / \mathrm{L}$ in $43.5 \%$ of Syrian patients and $62.2 \%$ of Turkish patients. The ratio of patients with serum phosphorus level of 1.13-1.77 mmol/L was lower in Syrian patients
Table 2. Dialysis practices in Syrian hemodialysis patients

\begin{tabular}{lcc}
\hline Variable & Parameters & Percentage (\%) \\
\hline Type of the dialyzer & High-flux & 40.9 \\
& Low-flux & 59.1 \\
& $<200$ & 1.4 \\
& $200-300$ & 30.7 \\
Blood flow rate (ml/min) & $300-400$ & 67.0 \\
& $>400$ & 0.9 \\
\hline
\end{tabular}




\section{Kidney Blood Pressure Research}

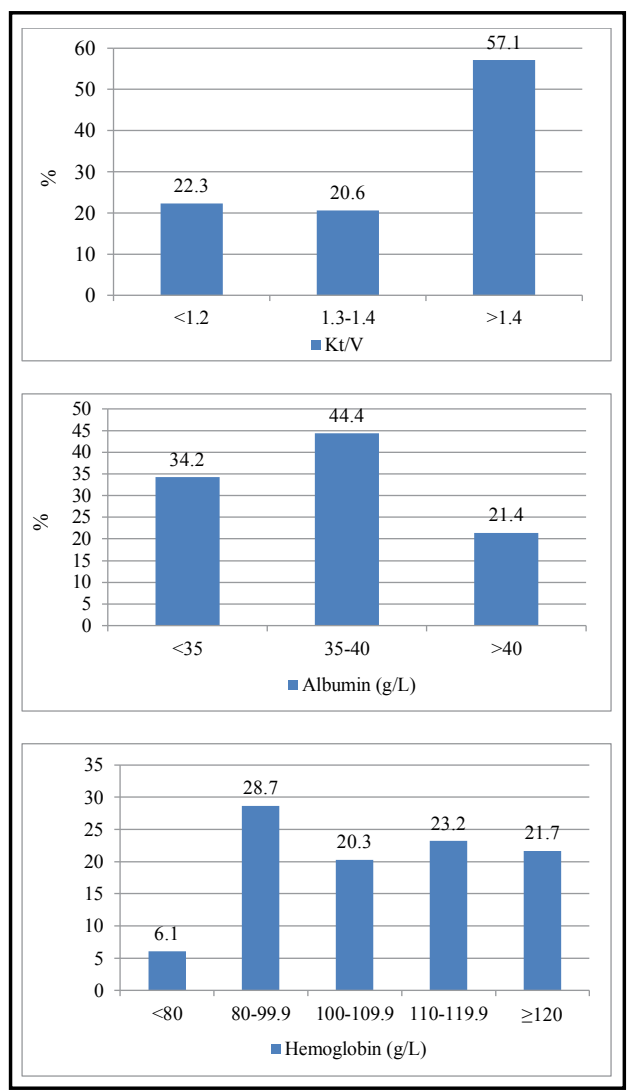

Fig. 2. $\mathrm{Kt} / \mathrm{V}$, albumin and hemoglobin levels of Syrian hemodialysis patients.

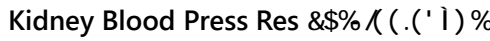

\begin{tabular}{|l|l|l|}
\hline DOI: 10.1159/000498832 & (c) 2019 The Author(s). Published by S. Karger AG, Basel \\
\hline
\end{tabular} Published online: 22 February 2019 www.karger.com/kbr

Gursu et al.: Syrian Refugee Hemodialysis Experience in Turkey

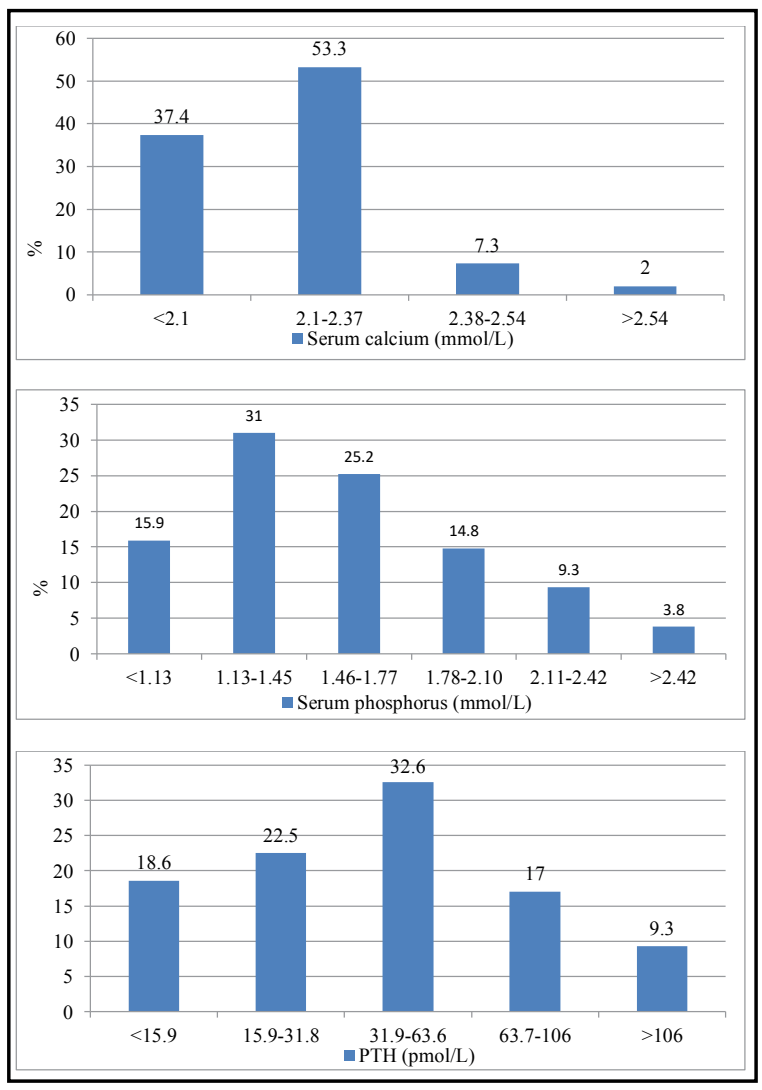

Fig. 3. Serum calcium, phosphorus and parathyroid hormone levels of Syrian hemodialysis patients.

compared to Turkish patients ( $\mathrm{p}=0.009)$. Iron treatment was used in $62.3 \%$ of Syrian patients while $53.5 \%$ of Turkish patients were using iron $(\mathrm{p}=0.015)$. Percentage of patients using antihypertensive drugs and ESA were similar with the Turkish patients.

\section{Mortality data}

Twenty Syrian HD patients (14 male, 6 female) died within the year 2016. Nine patients were in the age range of 45-64 years, six were in the range of 65-74 years, four patients were above the age of 74 and one patient was below 45 years of age. The cause of death was cardiovascular events in nine, cerebrovascular event in two, infection in three, malignancy in one, pulmonary disease in one patient while the cause of death was unknown in four patients. The overall annual mortality rate of Syrian patients $(5.7 \%)$ was lower than Turkish HD population, which was reported to be $15 \%$ in the Registry of Turkish Society of Nephrology in 2015 [14].

\section{Discussion}

The war affected Syrian HD patients both in their own country and in the countries where they were living as refugees. The exact number of patients affected is not known due to lack of data from Syria during the war. But according to the older report of Syrian Ministry of Health released in 2005 [8], we can guess that thousands of them are affected. These effects are economic and social in nature both in short and long term. Three countries in the field, namely Turkey, Lebanon and Jordan accepted the largest number of refugees up to now. A recent survey conducted by ISN reported 631 refugees were dialyzed in the 298 


\section{Kidney \\ Blood Pressure Research}

Table 3. Comparison of data of Syrian and Turkish patients

\begin{tabular}{lccc}
\hline Dialysis Variables & Parameters & Syrian Group (\%) & Turkish Group (\%) \\
\hline Type of the dialyzer & High-flux & 40.9 & 63.7 \\
& Low-flux & 59.1 & 36.3 \\
Blood flow rate (ml/min) & $<200$ & 1.4 & 4.7 \\
& $200-300$ & 30.7 & 13.9 \\
& $300-400$ & 67.0 & 69.5 \\
Vascular access & $>400$ & 0.9 & 11.9 \\
& AV fistula & 72.4 & 80.3 \\
& AV graft & 0.3 & 1.5 \\
Kt/V & Tunnelled catheter & 18.3 & 14.4 \\
& Untunnelled catheter & 9.0 & 3.8 \\
Serum albumin & $\leq 1.2$ & 22.3 & 9.8 \\
& $1.2-1.4$ & 20.6 & 20.3 \\
& $>1.4$ & 57.1 & 69.9 \\
Hemoglobin & $<35 \mathrm{~g} / \mathrm{L}$ & 34.2 & 13.4 \\
& $35-40 \mathrm{~g} / \mathrm{L}$ & 44.4 & 49.2 \\
& $>40 \mathrm{~g} / \mathrm{L}$ & 21.4 & 37.4 \\
& $<80 \mathrm{~g} / \mathrm{L}$ & 6.1 & 2.5 \\
& $80-99.9 \mathrm{~g} / \mathrm{L}$ & 28.7 & 12.2 \\
& $100-109.9 \mathrm{~g} / \mathrm{L}$ & 20.3 & 26.1 \\
Serum phosphorus & $110-119.9 \mathrm{~g} / \mathrm{L}$ & 23.2 & 36.1 \\
& $\geq 120 \mathrm{~g} / \mathrm{L}$ & 21.7 & 23.1 \\
& $<1.13 \mathrm{mmol} / \mathrm{L}$ & 15.9 & 7.9 \\
& $1.13-1.45 \mathrm{mmol} / \mathrm{L}$ & 31.0 & 30.0 \\
& $1.46-1.77 \mathrm{mmol} / \mathrm{L}$ & 25.2 & 33.1 \\
& $1.78-2.10 \mathrm{mmol} / \mathrm{L}$ & 14.8 & 18.7 \\
& $2.11-2.42 \mathrm{mmol} / \mathrm{L}$ & 9.3 & 7.7 \\
& $>2.42 \mathrm{mmol} / \mathrm{L}$ & 3.8 & 2.6 \\
\hline
\end{tabular}

centers responding to the survey [15]. Thirty-three centers reported to refuse dialysis to at least one refugee. There was a center which reported that they refused about 250 patients due to lack of resources which is the main cause of refusal by other centers too [15].

Our study reports the largest number of Syrian refugees $(n=345)$ who were undergoing maintenance HD in Turkey. Although there were some differences in dialysis practice or medical care parameters, we have observed that Syrian refugees had a high quality dialysis care with a low mortality rate. The low mortality might be attributed to both full reimbursement and provision of dialysis services with medicine coverage and young age of Syrian HD patients.

Nephrology community all over the world is confronted with the increasing number of refugee HD patients, and concerned with the sources available for their health expenditures [16]. After Syrian conflict started in 2011, Turkey has hosted almost 3 million refugees. Among them, there were patients with kidney diseases (the actual number is not known) who are in the predialysis period or who need chronic dialysis treatment. All refugees who need chronic HD had started their HD regimens either in state-owned or private clinics. All the costs including medication have been covered by the government.

Syrian HD patients were relatively young in Turkey. This may be simply explained with the fact that usually younger people are able to walk out from their countries while older ones stay. In a study examining 1212 refugees and immigrant population in Italy, the median age was 32 years [17]. In a recent report of AFAD, age distribution of Syrian refugees in Turkey was reported as $37.8 \%$ in $18-29$ years, $35.7 \%$ in $30-44$ years, and $20.6 \%$ in $45-59$ years old while only $6.0 \%$ were in 60-69 years old group [6]. 


\section{Kidney Blood Pressure Research}

Kidney Blood Press Res

\begin{tabular}{l|l}
\hline DOI: $10.1159 / 000498832$ & (c) 2019 The Author(s). Published by S. Karger AG, Basel
\end{tabular}

Published online: 22 February 2019

www.karger.com/kbr

Gursu et al.: Syrian Refugee Hemodialysis Experience in Turkey

The majority of Syrian patients receiving HD treatment in Turkey had total dialysis duration less than five years. This is consistent with the younger age of the group. The duration of HD treatment within Turkey was even shorter. $45 \%$ of the patients presented in this study had HD treatment for less than six months, which may be related to the continuous movement of the refugee population. This is in consistence with the findings of the survey conducted by AFAD [6]. It was reported that Syrian refugees have lived in Turkey for 21.2 months on average, and $20.6 \%$ of them have been in Turkey for less than six months [6]. Beyond that, some patients may have predialysis care in Turkey and have started hemodialysis in Turkey, but the data was not available in the registry.

Syrian refugees had less positive hepatitis B serology compared to Turkish HD patients [14]. Hepatitis C prevalence (6.7\%) in this cohort is similar to Turkish population [14], but very low compared to the Syrian patients receiving dialysis in Jordan (14\%) [12].

Catheter use as vascular access was higher than the rates recommended by international guidelines. The underlying reason for this fact is not easily explained as the data for predialysis care was missing in this registry. 'Were these patients had catheter insertion in Syria before their exodus?' or 'were these patients admitted very late to Nephrology care in Turkey and had an urgent start to dialysis without proper predialysis care?" are the remaining questions to be answered.

Most of the Syrian refugee HD patients had thrice weekly treatment schedule. This is a striking finding considering the unplanned entry of the refugees to Turkey and the subsequent sudden and great burden to the Turkish health system. The devoted health personnel and the government who provided reimbursement of all health expenditures of these refugees rendered this service possible. In a study about the HD practices in Syria, it was reported that thrice weekly regime was $13.6 \%$ in 2009, which was before the conflict [9]. Moreover, AlMakki et al. [18] claimed that the dialysis frequency in a center in Aleppo was once or twice a week but rarely thrice a week. Among Syrian patients receiving dialysis in Jordan only 57\% had dialysis three times a week [12]. Dialysis is a very costly treatment and countries all over the world may have different policies about reimbursement of refugees' chronic health problems. Undocumented immigrants in USA are ineligible for federally funded government programs like Medicare and non-emergency Medicaid [3]. The recent report by Van Biesen et al. [15] has documented the problems encountered in dialyzing refugees by a survey in 298 individual dialysis centers from 45 countries. These centers had dialyzed 631 refugees in the 4 months before the survey. Thirty-three centers reported that they have refused dialysis at least to one or more refugees; one center very close to an active war zone reported to refuse 250 patients because of no resources. One center in Western Europe declined 25 refugee patients (but accepted 25 others) as the cost was to be supported by the nephrology department. Other centers reporting high refusal rates stated that they had requested patients to pay for their treatment [15].

The type of the dialyzer used for Syrian patients was not different than Turkish patients' dialyzers. Blood flow rate above $300 \mathrm{ml} / \mathrm{min}$ was relatively frequent. The underlying cause is not clear enough but may be related with body mass index.

$\mathrm{Kt} / \mathrm{V}$, albumin, hemoglobin levels, mineral-bone disorder parameters and need for antihypertensive drugs were used as measures of dialysis adequacy. Majority of $22.3 \%$ of patients had Kt/V value of 1.2 or less. This may be related to both high usage of catheters and low blood flow rate in this group of patients. Another important point in analysis of Kt/V is the fact that most refugees were having dialysis for a short time span in Turkey. Almost half of the patients ( $45 \%$ Syrian refugees) were having dialysis less than six months in Turkey. The Kt/V values may improve in the following months.

The ratio of patients with serum albumin level less than $35 \mathrm{~g} / \mathrm{L}$ was $34.2 \%$. Similar to the Kt/V levels, this may also be related to short time of dialysis and some unknown factors. Besides that, it is known that refugees who are voluntarily residing outside government camps had little income, so had inadequate nutrition [19]. Hypoalbuminemia thus may be a sign of malnutrition. Housing conditions outside the camps are not optimal and may 


\section{Kidney Blood Pressure Research}

predispose refugees to infectious diseases by which albumin levels decrease as a negative acute phase reactant.

The ratio of Syrian refugees with hemoglobin levels $\geq 100 \mathrm{gr} / \mathrm{L}$ was $65.2 \%$. This may reflect the adequacy of dialysis time and ultrafiltration rates, and ability to give these patients enough medical treatment like ESA and parenteral iron which are fully covered. Another result of this policy may be the acceptable rates of patients having target serum levels of calcium, phosphorus and PTH.

The exact mortality rate of Syrian patients is difficult to estimate with the available data. During 2016 however, 20 patients among 345 have died and annual mortality is assumed to be $5.7 \%$. This figure is much lower than Turkish patients' mortality rate $(15 \%)$. The difference may be related both the young age of Syrian refugees and short time span of dialysis in Turkey. The low mortality rate is still important regarding the many difficulties encountered in dialyzing refugees [15]. Complete reimbursement of the HD procedure and medications may benefit refugees for having adequate dialysis and low mortality rate. Data about the outcome of refugee HD patients are very limited in the literature. A report from 1993 has shown that insufficient access to dialysis and substantial shortening of treatments resulted in higher mortality in dialysis patients during the war in Iraq [20]. Longer follow up data in Syrian refugees will provide more insight in the outcome of these patients.

There are some limitations of this study. The data is a registry data and personal clinical profile of the patients beyond laboratory values and medicine history is lacking. Lack of data about the underlying etiology of renal failure and predialysis care precluded interpretation of some findings. The short time span of dialysis care in Turkey is another limitation of the study. The data about psychosocial aspects of refugee patients or the encountered problems till they reach dialysis care were missing.

\section{Conclusion}

This study with the largest number of Syrian refugees undergoing maintenance HD showed good dialysis practices, acceptable values for dialysis adequacy and biochemical parameters along with lower mortality compared to native HD population of Turkey. Longer follow up of these patients will enrich the knowledge related to dialysis care of refugee population in all over the world.

\section{Acknowledgements}

We thank all physicians that enter data to TDIS, all the staff that gather together the data in TDIS, and authorities of the Ministry of Health for sharing the data with us.

\section{Disclosure Statement}

Meltem Gursu, Kenan Ates, Pinar Guneser Yavas, Murat Ozturk, Bulent Altun and Turgay Arinsoy have nothing to disclose. Mustafa Arici reports personal fees from Amgen, Astra Zeneca, Daiichi Sankyo, MSD, Sanofi, outside the submitted work. Rumeyza Kazancioglu reports personal fees from Baxter, outside the submitted work. 


\section{Kidney \\ Blood Pressure Research}

\section{References}

1 UNHCR: The UN Refugee Agency. URL: http://www.unhcr.org.

2 Data of AFAD. URL: https://www.afad.gov.tr/tr/13016/Infografik/grafik/18383.

3 Eleanor D. Kinney: Realizing the International Human Right to Health for Non Citizens in the United States. Notre Dame Journal of International, Comparative, \& Human Rights Law 2011;1:102-105.

4 Cervantes L, Fischer S, Berlinger N, Zabalaga M, Camacho C, Linas S, Ortega D: The Illness Experience of Undocumented Immigrants with End-stage Renal Disease. JAMA Intern Med 2017; 177:529-535.

5 Cervantes L, Tuot D, Raghavan R, Linas S, Zoucha J, Sweeney L, Vangala C, Hull M, Camacho M, Keniston A, McCulloch CE, Grubbs V, Kendrick J, Powe NR: Association of Emergency-Only vs Standard Hemodialysis With Mortality and Health Care Use Among Undocumented Immigrants With End-stage Renal Disease. JAMA Intern Med 2018;178:188-195.

6 Balcilar M: Health Status Survey of Syrian Refugees in Turkey. Non-communicable Disease Risk Factors Surveillance among Syrian Refugees Living in Turkey. URL: https://sbu.saglik.gov.tr/Ekutuphane/kitaplar/ suriyeli\%20m\%C3\%BClteci\%20ingilizce.pdf.

7 Doner P, Ozkara A, Kahveci R: Syrian refugees in Turkey: numbers and emotions. Lancet 2013;382:764.

-8 Saeed B, Derani R, Hajibrahim M, Roumani J, Al-Shaer MB, Saeed R, Damerli S, Al-Saadi R, Kayyal B, Haddad M: Organ failure in Syria: Initiating a national deceased donation program. Saudi J Kidney Dis Transpl 2007;18:270-276.

9 Moukeh G, Yacoub R, Fahdi F, Rastam S, Albitar S: Epidemiology of hemodialysis patients in Aleppo city. Saudi J Kidney Dis Transpl 2009;20:140-146.

-10 Isreb M, Alyousef M, Obaid N, Abbara A, Sekkarie M: Effect of besiegement on non-communicable diseases: haemodialysis. Lancet 2016;388:2350.

-11 Akbalik Kara M, Demircioglu Kilic B, Col N, Ozcelik AA, Buyukcelik M, Balat A: Kidney Disease Profile of Syrian Refugee Children. Iran J Kidney Dis 2017;11:109-114.

$\checkmark 12$ Isreb MA, Kaysi S, Rifai AO, Al Kukhun H, Al-Adwan SAS, Kass-Hout TA, Sekkarie MA: The Effect of War on Syrian Refugees with End-Stage Renal Disease. Kidney Int Rep 2017;2:960-963.

13 Isreb MA, Rifai AO, Murad LB, Al-Makki A, Al-Saghir F, Sekkarie MA: Care and outcomes of end-stage kidney disease patients in times of armed conflict: recommendations for action. Clin Nephrol 2016;85:281-288.

14 Registry of the Nephrology, Dialysis and Transplantation in Turkey-2015. URL: http://www.nefroloji.org. tr/folders/file/2015_REGISTRY_kontrol_v2.pdf

-15 van Biesen W, Vanholder R, Vanderhaegen B, Lameire N, Wanner CWiecek A, Sever MS, Feehally J, Kazancioglu R, Rondeau E, Levin A, Harris D: Renal replacement therapy for refugees with end-stage kidney disease: an international survey of the nephrological community. Kidney Int Suppl 2016;6:35-41.

16 van Biesen W, Vanholder R, Ernandez T, Drewniak D, Luyckx V: Caring for Migrants and Refugees With EndStage Kidney Disease in Europe. Am J Kidney Dis. Am J Kidney Dis 2018;71:701-709.

17 Coppola N, Alessio L, Gualdieri L, Pisaturo M, Sagnelli C, Minichini C, Di Caprio G, Starace M, Onorato L, Signoriello G, Macera M, Angelillo IF, Pasquale G, Sagnelli E: Hepatitis B virus infection in undocumented immigrants and refugees in Southern Italy: demographic, virological, and clinical features. Infect Dis Poverty 2017;6:33.

18 Al-Makki A, Rifai AO, Murad L, Zanabli AR, Kayal A, Soudan K, Kherallah M, Alsaghir F, Sekkarie M: The Syrian national kidney foundation: Response for the need of kidney patients during the crisis. Avicenna J Med 2014;4:54-57.

19 Republic of Turkey, Prime Ministry, Disaster and Emergency Management Presidency: Syrian refugees in Turkey, 2013. Field Survey Results. URL: https://www.afad.gov.tr/upload/Node/3926/xfiles/syrianrefugees-in-turkey-2013_print_12_11_2013_eng.pdf.

20 el-Reshaid K, Johny KV, Georgous M, Nampoory MR, al-Hilal N: The impact of Iraqi occupation on end-stage renal disease patients in Kuwait, 1990-1991. Nephrol Dial Transplant 1993;8:7-10. 